\title{
Skin Bleaching and Dermatologic Health of African and Afro-Caribbean Populations in the US: New Directions for Methodologically Rigorous, Multidisciplinary, and Culturally Sensitive Research
}

Emma K. T. Benn · Andrew Alexis · Nihal Mohamed • Yan-Hong Wang •

Ikhlas A. Khan · Bian Liu

Received: September 19, 2016 / Published online: November 11, 2016

(C) The Author(s) 2016. This article is published with open access at Springerlink.com

\section{ABSTRACT}

Skin-bleaching practices, such as using skin creams and soaps to achieve a lighter skin tone, are common throughout the world and are triggered by cosmetic reasons that oftentimes have deep historical, economic, sociocultural, and psychosocial roots. Exposure to chemicals in the bleaching products, notably, mercury (Hg), hydroquinone, and

Enhanced content To view enhanced content for this article go to http://www.medengine.com/Redeem/ C417F0602B717BF5.

E. K. T. Benn $(\varangle) \cdot$ B. Liu

Department of Population Health Science and Policy, Center for Biostatistics, Institute for

Translational Epidemiology, Icahn School of

Medicine at Mount Sinai, New York, NY, USA

e-mail: emma.benn@mountsinai.org

\section{A. Alexis}

Department of Dermatology, Skin of Color Center,

Mount Sinai St. Luke's and Mount Sinai West,

New York, NY, USA

\section{N. Mohamed}

Department of Urology, Tisch Cancer Institute, Icahn School of Medicine at Mount Sinai, New York, NY, USA

\section{Y.-H. Wang · I. A. Khan}

National Center for Natural Products, School of Pharmacy, University of Mississippi, Oxford, MS, USA steroids, has been associated with a variety of adverse health effects, such as Hg poisoning and exogenous ochronosis. In New York City (NYC), skin care product use has been identified as an important route of $\mathrm{Hg}$ exposure, especially among Caribbean-born blacks and Dominicans. However, surprisingly sparse information is available on the epidemiology of the health impacts of skin-bleaching practices among these populations. We highlight the dearth of large-scale, comprehensive, community-based, clinical, and translational research in this area, especially the limited skin-bleaching-related research among non-White populations in the US. We offer five new research directions, including investigating the known and under-studied health consequences among populations for which the skin bleach practice is newly emerging at an alarming rate using innovative laboratory and statistical methods. We call for conducting methodologically rigorous, multidisciplinary, and culturally sensitive research in order to provide insights into the root and the epidemiological status of the practice and provide evidence of exposure-outcome associations, with an 
ultimate goal of developing potential intervention strategies to reduce the health burdens of skin-bleaching practice.

Keywords: Clinical research; Dermatology; Environmental health; Skin bleaching; Skin of color

\section{CURRENT CONTEXT}

Skin-bleaching practices, such as using skin-lightening creams and soaps to achieve a lighter skin tone or to "whiten" skin, are common among non-White populations throughout the world, triggered by deep historical, economic, sociocultural, and psychosocial roots [1-5]. The exact prevalence of this practice among different population groups across different geographic areas is not known, and the existing estimates (e.g., 25-67\%) have most likely been underestimated, since some women may be reluctant to admit the practice because of the stigma surrounding these complexion-altering behaviors $[6,7]$. In addition, skin bleaching is becoming more common among men and young adults, including teenagers $[3,5,8]$. Prenatal exposure is also likely since pregnant women have been reportedly using skin-bleaching products $[9,10]$. While skin-bleaching research has been heavily focused on darker-skinned African populations, it has become an increasing concern in Jamaica and other Afro-Caribbean countries [6, 8, 11]. More specifically, Hope [5] has posited that for Jamaicans, skin-bleaching practices have transitioned from historically being a response to economic and complexion-related oppression of the darker-skinned working class and poor populations to a current expression of "...fashion and ungendered rites of beauty."

Skin bleaching has been associated with a variety of known adverse health effects ranging from dermatitis to exogenous ochronosis (Fig. 1), steroid acne (Fig. 2), mercury (Hg) poisoning, and nephrotic syndrome, which are linked to ingredients such as hydroquinone, corticosteroids, and $\mathrm{Hg}$ [1, 4, 6, 12-18]. Due to health concerns, some of these chemicals are regulated [19-23]. However, studies have found products containing the aforementioned ingredients with above legal limits, including products from the USA and European Union, where regulations are stricter and better implemented. In addition, access to a variety of legal and illegal skin-bleaching productsincluding prescription strength hydroquinone and topical corticosteroids-is made easy through online purchases, global travel, and immigration [17, 18, 24-26].

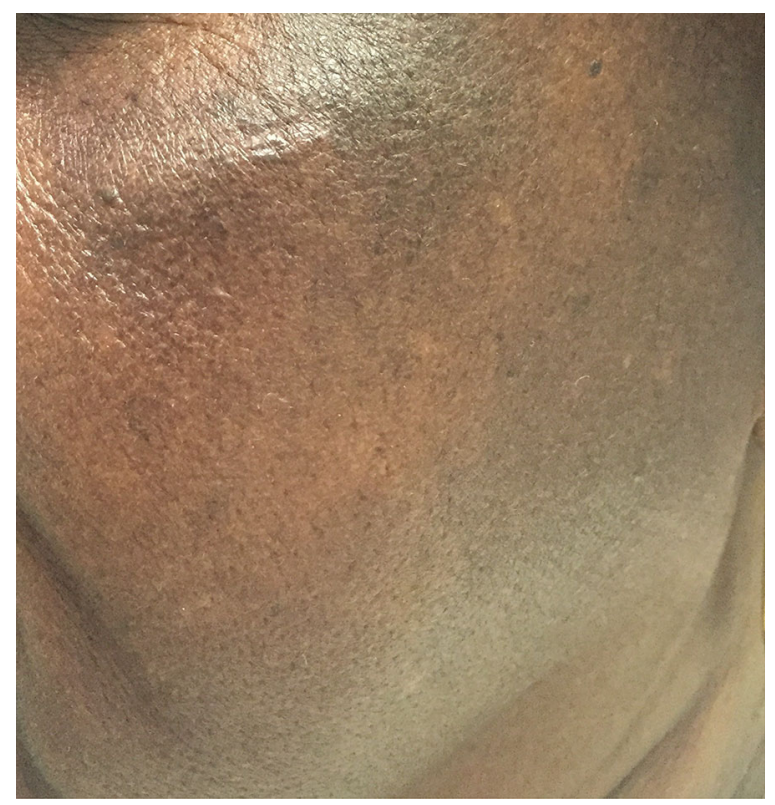

Fig. 1 Exogenous ochronosis on the face of a woman with a history of hydroquinone use 


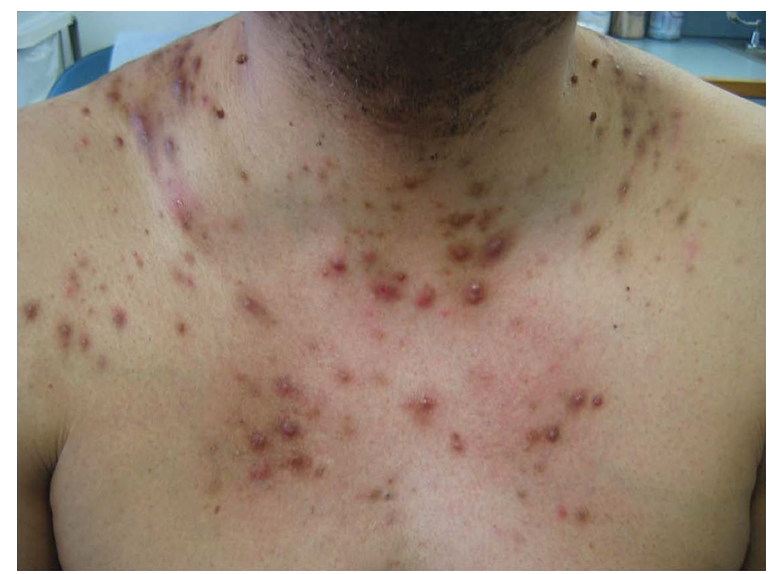

Fig. 2 Steroid acne on the chest following use of a corticosteroid containing bleaching cream for over 1 year

Skin bleaching is not uncommon in the US, and the health burden of skin-bleaching practices is not evenly distributed among the population. The 2004 New York City (NYC) local health and nutrition examination survey identified skin care product use as an important route of $\mathrm{Hg}$ exposure, especially among Caribbean-born blacks and Dominicans in NYC, with mean urine $\mathrm{Hg}$ concentrations 1.3-2.1 times higher than that of whites and other racial/ethnic groups [26]. Despite these reports, surprisingly sparse epidemiological studies are available regarding the health impacts of skin-bleaching practices on Afro-Caribbean immigrant groups in the US. In fact, this topic has gained very little attention among clinical and translational researchers in the US, with existing studies primarily limited to investigations of outbreaks of $\mathrm{Hg}$ poisoning related to the use of skin-whitening products [27-29].

\section{NEW DIRECTIONS}

Thus, we have proposed five new directions for research in this area. First, we must comprehensively estimate the prevalence of skin bleaching among both previously studied populations and populations, like those from Afro-Caribbean countries such as Jamaica, for which this practice is newly emerging at an alarming rate. While it is easier to focus just on newly emerging populations by geography, we should also examine the prevalence of this practice among other under-studied risk groups such as men, younger populations, and pregnant mothers.

Second, besides the known dermatologic effects of skin bleach, such as dermatitis, exogenous ochronosis, and acne, we should also expand our focus to long-term health consequences such as cancer as well as interactions between physical and psychosocial health outcomes. The potential carcinogenic effects of this practice may not be solely limited to exposure to hydroquinone, a primary metabolite of benzene, which is not currently classified as carcinogenic to humans because of conflicting results, though recent evidence suggests that hydroquinone can generate DNA damages and immunosuppressive responses $[18,25,26$, 30-34]. Attention should also be given to potential increased susceptibility to skin cancer resulting from alterations of melanin production among those who practice skin bleaching, especially among populations living in tropical regions with strong UV radiation. While their darker skin is considered to be protective of sun-induced skin cancer, the carcinogenic effect of melanogenesis inhibition resulting from skin bleaching remains to be explored $[35,36]$.

Third, we should identify all skin-bleaching products used and scientifically evaluate ingredients such as metals, hydroquinone, and the steroid composition of these exposures using specialized laboratory methods [37, 38]. Most existing studies focus on only one of the 
ingredients in these beauty products, which has hindered investigations of the health effects of exposure to mixtures from multiple ingredients. In addition, because self-mixing of a variety of chemicals (e.g., combining multiple commercial skin-bleaching products with hydrogen peroxide) is not uncommon, investigations of harmful chemical compositions in these home-made products should also be considered.

Fourth, we should empirically compute the dose-response relationships between the aforementioned exposures and associated dermatologic outcomes across various usage patterns and durations, which also require using innovative biomarkers to assess shortand long-term exposures to skin-bleaching products.

Last, but not the least, we posit that an integrative approach that brings together a multidisciplinary team of experts in dermatology, environmental epidemiology, biostatistics, pharmacology, behavioral psychology, and community health will be best suited to tackle this complex public health problem. This would allow for a large-scale, methodologically rigorous approach that can simultaneously explore the psychosocial motivations underlying this practice, the toxicological risks, and causal relationships between skin-bleaching product-related exposures and health outcomes. Existing studies often employ a single-aspect design highlighting only one of three topic areas: (1) psychosocial implications, (2) dermatological health effects, or (3) an exposure assessment of the skin-bleaching practice. A well-designed, comprehensive integrative study would give researchers the latitude to investigate the underlying roots and epidemiologic status of skin bleaching while simultaneously providing evidence of exposure-outcome associations, which would serve as a necessary strategy if our ultimate goal is to develop efficacious interventions that can effectively reduce the health burdens of this practice.

However, we understand that this interdisciplinary undertaking is challenging, given many in these communities, as we have observed at our institution, may not associate skin-related changes to their skin-bleaching practices. Limited access to dermatologists among the population at risk may also contribute to under-detection of complications of skin bleaching. Moreover, the underlying stigma surrounding this behavior might prevent these individuals from communicating their concerns to clinicians whom they perceive to have inadequate understanding of the cultural context. While these are all challenges that we must work on with these communities to overcome, from a research perspective, we still have a major difficulty in identifying patients with specific diagnoses resulting from skin bleaching because identifying cases requires an index of suspicion on the part of the clinician and specific inquiry into skin care practices, which may not be performed consistently or documented in the medical record [14].

\section{CONCLUSION}

In summary, if we are to adequately care for clinically vulnerable, skin-bleaching subpopulations of the African and Afro-Caribbean immigrant communities, and other under-studied populations in the US, we must first understand the magnitude of the problem, draw valid causal inference about the harmful exposures from the skin-bleaching products and their resulting health problems, and subsequently provide culturally sensitive 
solutions that do not further stigmatize these populations. This is especially important since skin bleaching may be a rational response to being born in racially and economically segregated societies, even if this practice may be viewed less favorably in the clinical and translational sector.

\section{ACKNOWLEDGEMENTS}

Sponsorship for this study was funded by a Transdisciplinary Center on Health Effects of Early Environmental Exposures P30 Core Center pilot grant (P30ES023515) at the Icahn School of Medicine at Mount Sinai. The authors would also like to acknowledge Ms. Richa Deshpande, a graduate research assistant at the Icahn School of Medicine at Mount Sinai, for her editorial assistance in the revision phase of the manuscript submission process. All named authors meet the International Committee of Medical Journal Editors (ICMJE) criteria for authorship for this manuscript, take responsibility for the integrity of the work as a whole, and have given final approval for the version to be published.

Disclosures. E.K.T. Benn, B. Liu, I.A. Khan, Y.-H. Wang, N. Mohamed, and A. Alexis have nothing to disclose.

Compliance with Ethics Guidelines. This article is based on previously conducted studies and does not involve any new studies of human or animal subjects performed by any of the authors.

Open Access. This article is distributed under the terms of the Creative Commons Attribution-NonCommercial 4.0 International License (http://creativecommons.org/licenses/ by-nc/4.0/), which permits any noncommercial use, distribution, and reproduction in any medium, provided you give appropriate credit to the original author(s) and the source, provide a link to the Creative Commons license, and indicate if changes were made.

\section{REFERENCES}

1. Dadzie OE, Petit A. Skin bleaching: highlighting the misuse of cutaneous depigmenting agents. J Eur Acad Dermatol Venereol JEADV. 2009;23(7):741-50.

2. Charles CAD. Skin bleachers' representations of skin color in Jamaica. J Black Stud. 2009;40(2):153-70.

3. Charles CAD. Skin bleaching, self-hate, and black identity in Jamaica. J Black Stud. 2003;33(6):711-28.

4. Ladizinski B, Mistry N, Kundu RV. Widespread use of toxic skin lightening compounds: medical and psychosocial aspects. Dermatol Clin. 2011;29(1):111-23.

5. Hope DP. From browning to cake soap: popular debates on skin bleaching in the Jamaican Dancehall. J Pan African Stud. 2011;4(4):165-94.

6. Mahe A. The practice of skin-bleaching for a cosmetic purpose in immigrant communities. J Travel Med. 2014;21(4):282-7.

7. Mahe A, Ly F, Aymard G, Dangou JM. Skin diseases associated with the cosmetic use of bleaching products in women from Dakar, Senegal. $\mathrm{Br} \mathrm{J}$ Dermatol. 2003;148(3):493-500.

8. James C, Seixas AA, Harrison A, Jean-Louis G, Butler M, Zizi F, Samuels A. Childhood physical and sexual abuse in Caribbean young adults and its association with depression, post-traumatic stress, and skin bleaching. J Depress Anxiety. 2016;5(1):214.

9. Mahe A, Perret JL, Ly F, Fall F, Rault JP, Dumont A. The cosmetic use of skin-lightening products during pregnancy in Dakar, Senegal: a common and potentially hazardous practice. Trans $\mathrm{R}$ Soc Trop Med Hyg. 2007;101(2):183-7.

10. Al-Saleh I. Potential health consequences of applying mercury-containing skin-lightening creams during pregnancy and lactation periods. Int J Hyg Environ Health. 2016;219(4-5):468-74. 
11. Petit A, Cohen-Ludmann C, Clevenbergh P, Bergmann JF, Dubertret L. Skin lightening and its complications among African people living in Paris. J Am Acad Dermatol. 2006;55(5):873-8.

12. Barr RD, Rees PH, Cordy PE, Kungu A, Woodger BA, Cameron HM. Nephrotic syndrome in adult Africans in Nairobi. Br Med J. 1972;2(5806):131-4.

13. Olumide YM, Akinkugbe AO, Altraide D, Mohammed T, Ahamefule N, Ayanlowo S, Onyekonwu C, Essen N. Complications of chronic use of skin lightening cosmetics. Int J Dermatol. 2008;47(4):344-53.

14. Chan TY. Inorganic mercury poisoning associated with skin-lightening cosmetic products. Clin Toxicol. 2011;49(10):886-91.

15. Levin CY, Maibach H. Exogenous ochronosis. An update on clinical features, causative agents and treatment options. Am J Clin Dermatol. 2001;2(4):213-7.

16. Simmons BJ, Griffith RD, Bray FN, Falto-Aizpurua LA, Nouri K. Exogenous ochronosis: a comprehensive review of the diagnosis, epidemiology, causes, and treatments. Am J Clin Dermatol. 2015;16(3):205-12.

17. Cristaudo A, D'llio S, Gallinella B, Mosca A, Majorani C, Violante N, Senofonte O, Morrone A, Petrucci F. Use of potentially harmful skin-lightening products among immigrant women in Rome, Italy: a pilot study. Dermatology 2013, 226(3):200-6.

18. Maneli MH, Wiesner L, Tinguely C, Davids LM, Spengane Z, Smith P, van Wyk JC, Jardine A, Khumalo NP. Combinations of potent topical steroids, mercury and hydroquinone are common in internationally manufactured skin-lightening products: a spectroscopic study. Clin Exp Dermatol. 2016;41(2):196-201.

19. EU. EU regulation 1223/2009, of the European parliament and of the Council of 30 November 2009, official J L 342/59 (22 December 2009). http:// refhub.elsevier.com/S0731-7085(13)00552-9/sbref00 15 2009. Accessed 14 May 2016.

20. FDA. Ruelmaking history for OTC skin bleaching drug products. http://www.fdagov/Drugs/Development ApprovalProcess/DevelopmentResources/Over-theCounterOTCDrugs/StatusofOTCRulemakings/ucm 072117htm\#Original 1990. Accessed 3 May 2016.

21. Thacker P. Another African nation bans popular skin-whitening creams. http://nytlive.nytimes. com/womenintheworld/2015/05/12/another-africannation-bans-popular-skin-whitening-creams/ 2015. Accessed 5 May 2016.
22. FDA. Guide to inspections of cosmetic product manufacturers: mercury compounds (codified at 21 CFR \$700.13). Federal Register February. 21CFR70013. http://www.accessdata.fda.gov/ scripts/cdrh/cfdocs/cfCFR/CFRSearchcfm?fr=70013\& SearchTerm=mercury 1995. Accessed 14 May 2016.

23. WHO. Mercury in skin lightening products. http:// www.whoint/ipcs/assessment/public_health/mercury_ flyerpdf 2011. Accessed 3 May 2016.

24. Mistry N, Shapero J, Kundu RV, Shapero H. Toxic effects of skin-lightening products in Canadian immigrants. J Cutan Med Surg. 2011;15(5):254-8.

25. Hamann CR, Boonchai W, Wen L, Sakanashi EN, Chu CY, Hamann K, Hamann CP, Sinniah K, Hamann D. Spectrometric analysis of mercury content in 549 skin-lightening products: is mercury toxicity a hidden global health hazard? I Am Acad Dermatol 2014, 70(2):281-7 (e283).

26. McKelvey W, Jeffery N, Clark N, Kass D, Parsons PJ. Population-based inorganic mercury biomonitoring and the identification of skin care products as a source of exposure in New York City. Environ Health Perspect. 2011;119(2):203-9.

27. CDC. Mercury poisoning associated with beauty cream-Texas, New Mexico, and California, 1995-1996. Centers for Disease Control and Prevention. MMWR 1996, 45(19):400-3.

28. CDC. Mercury exposure among household users and nonusers of skin-lightening creams produced in Mexico-California and Virginia, 2010. Centers for Disease Control and Prevention. MMWR 2012, 61(2):33-6.

29. Weldon MM, Smolinski MS, Maroufi A, Hasty BW, Gilliss DL, Boulanger LL, Balluz LS, Dutton RJ. Mercury poisoning associated with a Mexican beauty cream. Western J Med. 2000;173(1):15-8.

30. Kooyers TJ, Westerhof W. Toxicology and health risks of hydroquinone in skin lightening formulations. J Eur Acad Dermatol. 2006;20(7):777-80.

31. O'Donoghue JL. Hydroquinone and its analogues in dermatology - a risk-benefit viewpoint. J Cosmet Dermatol. 2006;5(3):196-203.

32. Re-evaluation of some organic chemicals, hydrazine and hydrogen peroxide. Proceedings of the IARC working group on the evaluation of carcinogenic risks to humans. Lyon, 17-24 February 1998. IARC monographs on the evaluation of carcinogenic risks to humans/World Health Organization, International Agency for Research on Cancer 1999, 71(Pt 1):1-315. 
33. Desmedt B, Van Hoeck E, Rogiers V, Courselle P, De Beer JO, De Paepe K, Deconinck E. Characterization of suspected illegal skin whitening cosmetics. J Pharmaceut Biomed. 2014;90:85-91.

34. Enguita FJ, Leitao AL. Hydroquinone: environmental pollution, toxicity, and microbial answers. Biomed Res Int. 2013;2013:542168.

35. Brenner $\mathrm{M}$, Hearing VJ. The protective role of melanin against UV damage in human skin. Photochem Photobiol. 2008;84(3):539-49.

36. Brenner M, Hearing VJ. Modifying skin pigmentation-approaches through intrinsic biochemistry and exogenous agents. Drug Discov Today Dis Mech. 2008;5(2):e189-99.
37. Desmedt B, Rogiers V, Courselle P, De Beer JO, De Paepe K, Deconinck E. Development and validation of a fast chromatographic method for screening and quantification of legal and illegal skin whitening agents. J Pharm Biomed Anal. 2013;83:82-8.

38. Wang YH, Avonto C, Avula B, Wang M, Rua D, Khan IA. Quantitative determination of alpha-arbutin, beta-arbutin, kojic acid, nicotinamide, hydroquinone, resorcinol, 4-methoxyphenol, 4-ethoxyphenol, and ascorbic acid from skin whitening products by HPLC-UV. J AOAC Int. 2015;98(1):5-12. 